\title{
Female professional divers. Similarities and differences between male and female professional divers
}

\author{
Ågot Irgens ${ }^{1}$, Kari Troland ${ }^{2}$, Marit Grønning ${ }^{1,3}$ \\ ${ }^{1}$ Norwegian Centre for Diving Medicine, Department of Occupational Medicine, Haukeland University Hospital, Bergen, Norway \\ ${ }^{2}$ Department of Occupational Medicine, Haukeland University Hospital, Bergen, Norway \\ ${ }^{3}$ Department of Clinical Medicine (K1), University of Bergen, Norway
}

\begin{abstract}
Background: The aim of the present study was to explore the potential differences between female and male professional divers with regards to demographics, diving certificates, areas of diving, diving activity and health effects.

Materials and methods: The Norwegian Labour Inspection Authority's Diving certificate register contains data on all professional inshore divers who have held a certificate at any time since 1980. Forty nine per cent of these divers responded to the "Norwegian diver 2011" questionnaire.

Results: Of these divers 64 female and 1327 male divers completed the questionnaire about their professional diving career, certificate, year of onset and the year they stopped diving professionally if they were not still active in the diving industry. The level of general education was higher among female divers. More males than females were fully certified in diving. The mean age was lower among female than male fully certified divers. Fully certified female divers reported a lower total number of dives, shallower dives and diving for a shorter period of time than the male divers. They also had a lower percentage of work within the quay/construction sector and more often worked as teachers/instructors. A lower percentage of fully certified females than males had experienced decompression sickness (16.7\% vs. 26.9\%). Life-threatening events and psychologically challenging events were less common among females, as were adverse health effects. No such gender differences were seen for divers with a restricted certificate.

Conclusions: The fully certified, female professional divers in our study had a very short diving career, reported fewer and shallower dives, and chose less physically demanding jobs than their male counterparts. They also had a higher level of education, reported less health problems and a better quality of life. The health effects seem to be related to the type of work rather than to gender.
\end{abstract}

(Int Marit Health 2017; 68, 1: 60-67)

Key words: female, professional diver, demographics, diving exposure, health effect

\section{INTRODUCTION}

Female professional divers are understudied. Apart from female shell fish divers such as the Ama-divers in Japan [1], most professional divers are men. However, some chapters in the book "Women and Pressure" [2] describe professional female divers in military diving and commercial diving. The latter involves rigorous work requiring physical strength and mechanical skills. The demand for physical strength, commuting and long working hours, may lead to gender differences in some areas of professional diving. Regulations regarding sick leave for pregnant women and the duration of maternity leave may also influence the choice of diving as a profession for women.

Norwegian inshore divers are certified by the Norwegian Labour Inspection Authority, an occupational safety and health agency of the Ministry of Labour. From 1980 onwards, the Labour Inspection Authority has operated the Norwegian Inshore Diver Registry (Diver Registry) which contains data on all divers with a certificate valid for professional inshore diving. The Norwegian Petroleum Safety 
Authority manages a separate registry for off-shore divers. Those diving both inshore and offshore are recorded in both registries. By August 2010, 7079 divers were included in the Diver Registry. Altogether 5854 of these could be identified with their national identification number, providing their home address.

Based on the Diver Registry we have previously conducted three register-based studies on mortality, cancer and the perinatal outcome in the children of male divers [3-5], as well as a comprehensive questionnaire study, the "Norwegian diver 2011" [6]. 6.6\% of those included in the Diver Registry are women. For clarity, these female divers had to be excluded in our previous paper on health effects in different areas of professional diving [7]. However, a curiosity arouse as to who these female divers were.

The aim of the present study was to explore the potential differences between female and male professional divers with regards to demographics, diving certificates, areas of diving, diving activity and health effects.

\section{MATERIALS AND METHODS}

A comprehensive questionnaire, the "Norwegian diver 2011" was prepared and sent by mail to all identified divers. A stamped return envelope was enclosed $[6,7]$. One reminder was sent.

Even if holding a valid certificate, some respondents might never have worked as divers. The responses to some critical questions were used as inclusion criteria to identify the actual professional divers:

- the year they started their professional diving career;

- a statement that they were still active as professional divers or stating the year they had finished their diving career;
- a statement that they had been an active professional diver for more than 1 year.

Diving certificates, class I, II, III, R and S are graded according to qualification. These qualifications are described in Table 1 together with diver characteristics, exposure variables, health related quality of life and symptoms. For divers holding more than one certificate, we used the highest level in our presentation ( ||$>|||>|>R>S$ ). Divers holding class I, II or III certificates are grouped together as "Fully certified divers" and divers holding class $\mathrm{R}$ or $\mathrm{S}$ as "Divers with restricted certificates".

The divers included in the study had given their written consent and the study was approved by the regional committee for medical and health research ethics (REC WEST 2010; 02529).

In this study we chose an explorative, hypothesis generating, approach. Only descriptive statistics are presented in tables and figures, due to the small numbers in the subgroups of divers. All analyses and graphs were performed by IBM, SPSS Statistics version 22 [8].

\section{RESULTS}

A total of 2848 divers responded to the questionnaire, of whom 185 women (response rate 49\%) and 2663 men (response rate 48\%). Seventy-seven female and 1628 male divers met the inclusion criteria. Of these, 64 females and 1327 males reported the type of diving certificate they held (Fig. 1).

For fully certified divers the mean age for females was lower than for males (Table 2). Irrespective of diving certificate, the education level was higher in female than male divers.

Table 1. Questionnaire - occupational diving and health effects

\begin{tabular}{|c|c|}
\hline Diver characteristics & Question details \\
\hline \multicolumn{2}{|l|}{ Certificate } \\
\hline \multirow[t]{3}{*}{$\begin{array}{l}\text { Fully certified divers } \\
\text { Class I, II or III }\end{array}$} & $\begin{array}{l}\text { Class I (Health and Safety executive part I equivalent) requires practical and theoretical } \\
\text { training to perform subsea work to depths of } 50 \mathrm{~m}\end{array}$ \\
\hline & $\begin{array}{l}\text { Class II (Closed bell) requires the same qualifications as lass I in addition to theoretical } \\
\text { education and practical training in saturation and bell diving }\end{array}$ \\
\hline & $\begin{array}{l}\text { Class III (Standard gear) requires the same qualifications as class I in addition to practical } \\
\text { training and education in specialised subsea work }\end{array}$ \\
\hline Restricted certified divers & Class $R$ is restricted to rescue diving to a maximum of $30 \mathrm{~m}$ \\
\hline Class $\mathrm{R}$ or $\mathrm{S}$ & $\begin{array}{l}\text { Class } S \text { is restricted to specific operations such as scientific diving with self-contained } \\
\text { underwater breathing apparatus gear to a maximum of } 30 \mathrm{~m} \text { and hyperbaric chamber attendants }\end{array}$ \\
\hline \multicolumn{2}{|l|}{ Age } \\
\hline The highest general education & $\begin{array}{l}\text { Five categories: Primary school, technical college, sixth-form college, university college } \\
\text { or university }\end{array}$ \\
\hline Occupational status & $\begin{array}{l}\text { Several options could be answered (active diver, employed in a diving firm - but } \\
\text { no diving, employed outside the diving industry, student) }\end{array}$ \\
\hline $\begin{array}{l}\text { Why did you end your professio- } \\
\text { nal diving career? }\end{array}$ & $\begin{array}{l}\text { Four options could be ticked off (health condition, working condition, better job } \\
\text { elsewhere, took a new education) }\end{array}$ \\
\hline
\end{tabular}


Table 1 (cont.). Questionnaire - occupational diving and health effects

\begin{tabular}{|c|c|c|c|}
\hline Diver characteristics & \multicolumn{2}{|l|}{ Question details } & Code \\
\hline \multicolumn{4}{|l|}{ Exposure variables } \\
\hline \multicolumn{4}{|l|}{ Total number of dives } \\
\hline The regular diving depth & \multicolumn{3}{|l|}{ The maximum of reported regular depth in SCUBA, helmet or hose, bounce diving } \\
\hline The number of years diving & \multicolumn{3}{|l|}{ Sum of year as self-employed, employed or other } \\
\hline Dives per year & \multicolumn{3}{|l|}{ Total number of dives per the number of years diving } \\
\hline Areas of professional diving & \multicolumn{3}{|c|}{$\begin{array}{l}\text { Nine options could be ticked off. The area of professional diving - work or worked in } \\
\text { "often", "seldom", "never". Included are areas the divers had ticked "often" versus the } \\
\text { remaining: quay/construction, fish farming, shellfish harvesting, offshore/oil related, } \\
\text { rescue, photographer, teacher/instructor, marine research, other }\end{array}$} \\
\hline The type of diving jobs & \multicolumn{3}{|c|}{$\begin{array}{l}\text { Seven options could be ticked off. Having professional diving jobs "often", "seldom", } \\
\text { "never". Included are jobs the divers had ticked "often" versus the remaining: construc- } \\
\text { tion work, inspection, maintenance/cleaning, placing cables/pipes, blasting, welding, } \\
\text { other }\end{array}$} \\
\hline Life threatening event & \multicolumn{2}{|c|}{$\begin{array}{l}\text { "Yes" if at least one of } 5 \text { events (gas cut, hit or almost hit by falling object, deviation } \\
\text { from vessel, being stuck under water or other life threatening events, other) had } \\
\text { been ticked off, otherwise "no" }\end{array}$} & Yes/no \\
\hline $\begin{array}{l}\text { Psychologically demanding } \\
\text { event }\end{array}$ & \multirow{2}{*}{\multicolumn{2}{|c|}{$\begin{array}{l}\text { "Yes" if at least one of the } 5 \text { events (psychologically challenging event: search for } \\
\text { drowned person, search for drowned children, loss of colleague or friend, experienced } \\
\text { near miss of colleague, other) had been ticked off, otherwise "no" }\end{array}$}} & Yes/no \\
\hline Objective health problems & & & \\
\hline Decompression sickness & \multicolumn{2}{|l|}{ Have you ever had an incidence of decompression sickness } & Yes/no \\
\hline Unconsciousness & \multicolumn{2}{|l|}{ Have you ever experienced unconsciousness during diving } & Yes/no \\
\hline \multicolumn{4}{|l|}{ Subjective health problems } \\
\hline $\begin{array}{l}\text { Effects of diving on present } \\
\text { health }\end{array}$ & \multicolumn{2}{|l|}{$\begin{array}{l}\text { Do you think diving has affected your health? "no effect", "positive effect" } \\
\text { or "negative effect" }\end{array}$} & Yes/no/none \\
\hline \multicolumn{2}{|l|}{ Symptoms reported } & No. & Score \\
\hline Lung & Cough and breathlessness & 7 & $\begin{array}{l}\text { Pos. } \\
\text { response/7 }\end{array}$ \\
\hline Hand or arm & $\begin{array}{l}\text { Tingling, pricking, numbness in hand, white fingers, pain and sensation, } \\
\text { stiffness in hand or arm, disabled due to symptoms }\end{array}$ & 8 & $\begin{array}{l}\text { Pos. } \\
\text { response/8 }\end{array}$ \\
\hline Musculoskeletal & $\begin{array}{l}\text { Pain or stiffness in neck, upper part of back, lumbar region, shoulder, } \\
\text { elbow, wrist/hand, groin, hip, knee, ankle/foot }\end{array}$ & 10 & $\begin{array}{l}\text { Pos. } \\
\text { response/10 }\end{array}$ \\
\hline Ear, nose, throat & $\begin{array}{l}\text { Pain or packed sinus, tinnitus, reduces hearing, external ear eczema/ } \\
\text { /complaints }\end{array}$ & 4 & $\begin{array}{l}\text { Pos. } \\
\text { response/4 }\end{array}$ \\
\hline Gastrointestinal & Heartburn, sour belch, stomach ache, diarrhoea, obstipated & 4 & $\begin{array}{l}\text { Pos. } \\
\text { response/4 }\end{array}$ \\
\hline Mental distress & $\begin{array}{l}\text { Attention or concentration problems, irritability, forgetfulness, anxiety, } \\
\text { depression, difficulties getting organised }\end{array}$ & 6 & $\begin{array}{l}\text { Pos. } \\
\text { response/6 }\end{array}$ \\
\hline Sleep & $\begin{array}{l}\text { Sleep problem during day, evening, night, waking up, could not fell asleep, } \\
\text { night mare, increased need of sleep, not refreshed after sleep }\end{array}$ & 7 & $\begin{array}{l}\text { Pos. } \\
\text { response/7 }\end{array}$ \\
\hline Sum symptom score & $\begin{array}{l}\text { Symptom score was calculated as no of positive response per total } \\
\text { number of symptoms }\end{array}$ & & $\Sigma$ scores \\
\hline Short-Form 12-Item Health & Physical functioning (PF) & & \\
\hline Survey (SF-12) & $\begin{array}{l}\text { Role physical (RP) } \\
\text { Bodily pain (BP) } \\
\text { General health (GH) } \\
\text { Vitality (VT) } \\
\text { Social functioning (SF) } \\
\text { Role emotional (RE) } \\
\text { Mental health (MH) }\end{array}$ & & \\
\hline
\end{tabular}




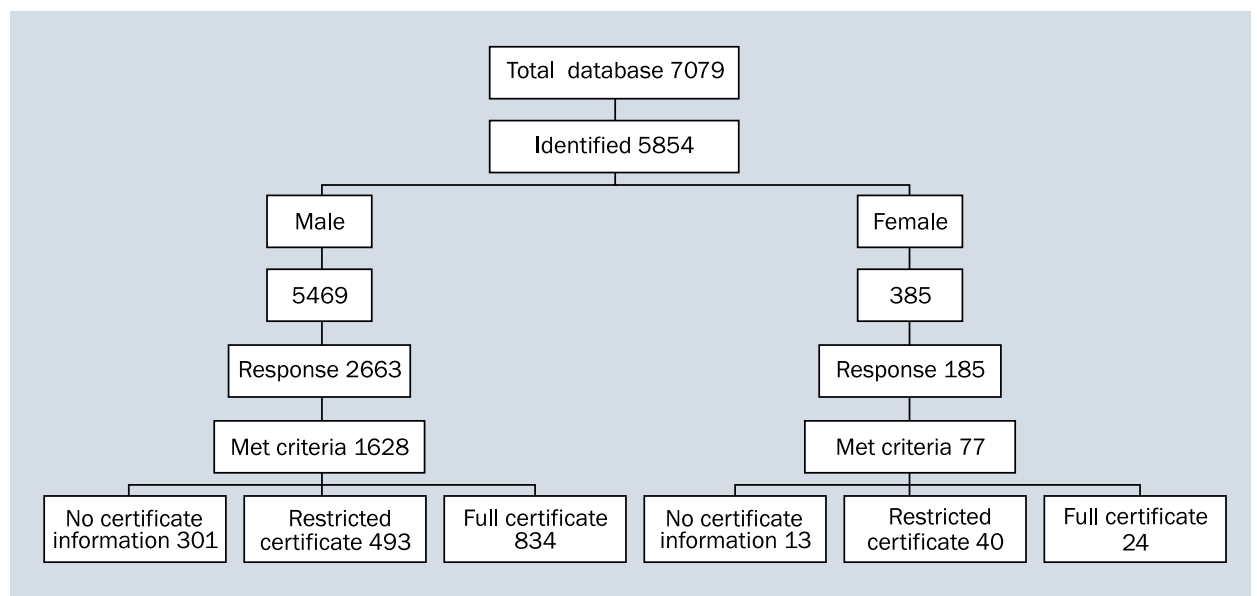

Figure 1. Flow chart regarding male and female divers included in the study. Data from the 'Norwegian diver 2011' project

Table 2. Age and level of education in male and female divers, fully and restricted certified. Data from the 'Norwegian diver 2011' project

\begin{tabular}{|c|c|c|c|c|c|c|c|c|}
\hline \multirow[b]{3}{*}{ Age } & \multicolumn{4}{|c|}{ Fully certified } & \multicolumn{4}{|c|}{ Restrictedly certified } \\
\hline & \multicolumn{2}{|l|}{ Female } & \multicolumn{2}{|l|}{ Male } & \multicolumn{2}{|c|}{ Female } & \multicolumn{2}{|l|}{ Male } \\
\hline & Mean & SD & Mean & SD & Mean & SD & Mean & SD \\
\hline All divers & 36 & 8.1 & 47 & 11.7 & 38 & 6.8 & 39 & 9.3 \\
\hline Active divers & 28 & 2.3 & 43 & 11.0 & 40 & 7.8 & 39 & 8.7 \\
\hline When leaving diving industry & 29 & 5.0 & 37 & 11.0 & 31 & 6.1 & 33 & 9.1 \\
\hline Highest education & $\mathbf{N}$ & $\%$ & $\mathbf{N}$ & $\%$ & $\mathbf{N}$ & $\%$ & $\mathbf{N}$ & $\%$ \\
\hline Primary school & 0 & 0 & 57 & 6.8 & 0 & 0 & 8 & 1.6 \\
\hline Technical college & 6 & 25.0 & 307 & 36.8 & 2 & 5.0 & 143 & 29.0 \\
\hline Sixth-form college & 2 & 8.3 & 136 & 16.3 & 1 & 2.5 & 67 & 13.6 \\
\hline University college & 8 & 33.3 & 227 & 27.2 & 10 & 25.0 & 137 & 27.8 \\
\hline University & 8 & 33.4 & 63 & 7.6 & 26 & 65.0 & 118 & 23.9 \\
\hline Missing & 0 & 0 & 44 & 5.3 & 1 & 2.5 & 20 & 4.1 \\
\hline
\end{tabular}

SD - standard deviation

The current occupational status differed between the two genders (Table 3). A lower percentage of females than males were active divers, and females more frequently listed "student" as their present occupational status. For former fully certified divers, there were only minor gender differences pertaining to reasons for having left the diving industry (Table 3).

Among fully certified divers, there were gender differences for the areas of professional diving (often employed in) and tasks (often performed) reported (Table 3). Compared to the men, a lower percentage of the women reported working in the area quay/construction sector, whilst a higher percentage worked within shellfish harvesting or as teachers/instructors compared to their male counterparts. A lower percentage of women than men reported the tasks of construction, inspection, maintenance/cleaning, placing cables/pipes, or blasting.

In divers with a restricted certificate minor gender differences were observed. More males were rescue divers and more females worked within marine research. Few tasks were reported by the female divers with a restricted certificate. Four female and four male divers with a restricted certificate had ticked off "often employed in oil-related industry". This is against the diving regulations.

Fully certified female divers reported a shorter diving career, a lower number and shallower dives as compared to males (Fig. 2). Among the divers with a restricted certificate no such gender differences were seen. However, for their years as active professional divers, females reported on average the same number of dives per year as males (Fig. 2). 
Table 3. The present occupational status and why divers left the diving industry, areas of professional diving and diving tasks often performed; among fully and restricted certified male and female divers. Data from the 'Norwegian diver 2011' project

\begin{tabular}{|c|c|c|c|c|c|c|c|c|}
\hline & \multicolumn{4}{|c|}{ Fully certified } & \multicolumn{4}{|c|}{ Restrictedly certified } \\
\hline & \multicolumn{2}{|c|}{ Female } & \multicolumn{2}{|c|}{ Male } & \multicolumn{2}{|c|}{ Female } & \multicolumn{2}{|c|}{ Male } \\
\hline & $\mathbf{N}$ & $\%$ & $\mathbf{N}$ & $\%$ & $\mathbf{N}$ & $\%$ & $\mathbf{N}$ & $\%$ \\
\hline \multicolumn{9}{|l|}{ Occupational status } \\
\hline Active diver & 6 & 25.0 & 286 & 34.3 & 10 & 25.0 & 225 & 45.6 \\
\hline Diving firm, no diving & 1 & 4.2 & 67 & 8.0 & 0 & 0 & 13 & 2.6 \\
\hline Outside diving industry & 16 & 66.7 & 430 & 51.6 & 28 & 70.0 & 320 & 64.9 \\
\hline Student & 3 & 12.5 & 21 & 2.5 & 4 & 10.0 & 29 & 5.9 \\
\hline \multicolumn{9}{|c|}{ Why did you end your professional diving career? } \\
\hline Health condition & 6 & 25.0 & 173 & 20.7 & 3 & 7.5 & 28 & 5.7 \\
\hline Working conditions & 3 & 12.5 & 119 & 14.3 & 3 & 7.5 & 25 & 5.1 \\
\hline Better job elsewhere & 8 & 33.3 & 258 & 30.9 & 11 & 27.5 & 94 & 19.1 \\
\hline Took new education & 6 & 25.0 & 209 & 25.1 & 7 & 17.5 & 101 & 20.5 \\
\hline \multicolumn{9}{|c|}{ Areas of professional diving (often performed) } \\
\hline Quay/construction & 7 & 29.2 & 456 & 54.7 & 0 & 0 & 40 & 8.1 \\
\hline Fish farming & 8 & 33.3 & 217 & 26.0 & 0 & 0 & 37 & 7.5 \\
\hline Shellfish harvesting & 4 & 16.7 & 43 & 5.2 & 0 & 0 & 24 & 4.9 \\
\hline Offshore/oil-related & 0 & 0 & 172 & 20.6 & 4 & 10.0 & 4 & 0.8 \\
\hline Rescue & 3 & 12.5 & 149 & 17.9 & 5 & 12.5 & 169 & 34.3 \\
\hline Photographer & 0 & 0 & 66 & 7.9 & 0 & 0 & 40 & 8.1 \\
\hline Teacher/instructor & 5 & 20.8 & 120 & 14.4 & 19 & 47.5 & 169 & 34.3 \\
\hline Marine research & 2 & 8.3 & 25 & 3.0 & 9 & 22.5 & 39 & 7.9 \\
\hline Other & 8 & 33.3 & 241 & 28.9 & 5 & 12.5 & 141 & 28.6 \\
\hline \multicolumn{9}{|c|}{ Diving tasks (often performed) } \\
\hline Construction work & 7 & 29.2 & 447 & 53.6 & 0 & 0 & 11 & 2.2 \\
\hline Inspection & 10 & 41.7 & 612 & 73.4 & 2 & 5.0 & 199 & 40.4 \\
\hline Maintenance/cleaning & 7 & 29.2 & 426 & 51.1 & 2 & 5.0 & 72 & 14.6 \\
\hline Placing cables/pipes & 4 & 16.7 & 354 & 42.4 & 0 & 0 & 13 & 2.6 \\
\hline Blasting & 1 & 4.2 & 202 & 24.2 & 0 & 0 & 13 & 2.6 \\
\hline Welding & 0 & 0 & 142 & 17.0 & 0 & 0 & 1 & 0.2 \\
\hline Other & 9 & 37.5 & 277 & 33.2 & 25 & 62.5 & 268 & 54.4 \\
\hline
\end{tabular}

For all questions several categories could be ticked off.

The prevalence of having experienced a life threatening event or a psychologically challenging event was lower for female than for male divers irrespective of their diving certificate (Table 4).

Among fully certified divers, a lower percentage of females than males reported decompression sickness or unconsciousness during diving (Table 4). In addition, a lower percentage of the female divers reported that diving had influenced their health in a negative way (Table 4). There were no such gender differences among divers with a restricted certificate.
In fully certified divers the total symptom score was lower for females than males (Fig. 3). In addition, health related quality of life was better for females than males for most SF-12 scales. These gender differences were not present in divers with a restricted certificate (Fig. 3).

\section{DISCUSSION}

In most aspects, female professional divers seemed to differ from male divers. The females were younger and had a higher level of education. They more often held restricted diving certificates or, if fully certified, had far less diving 


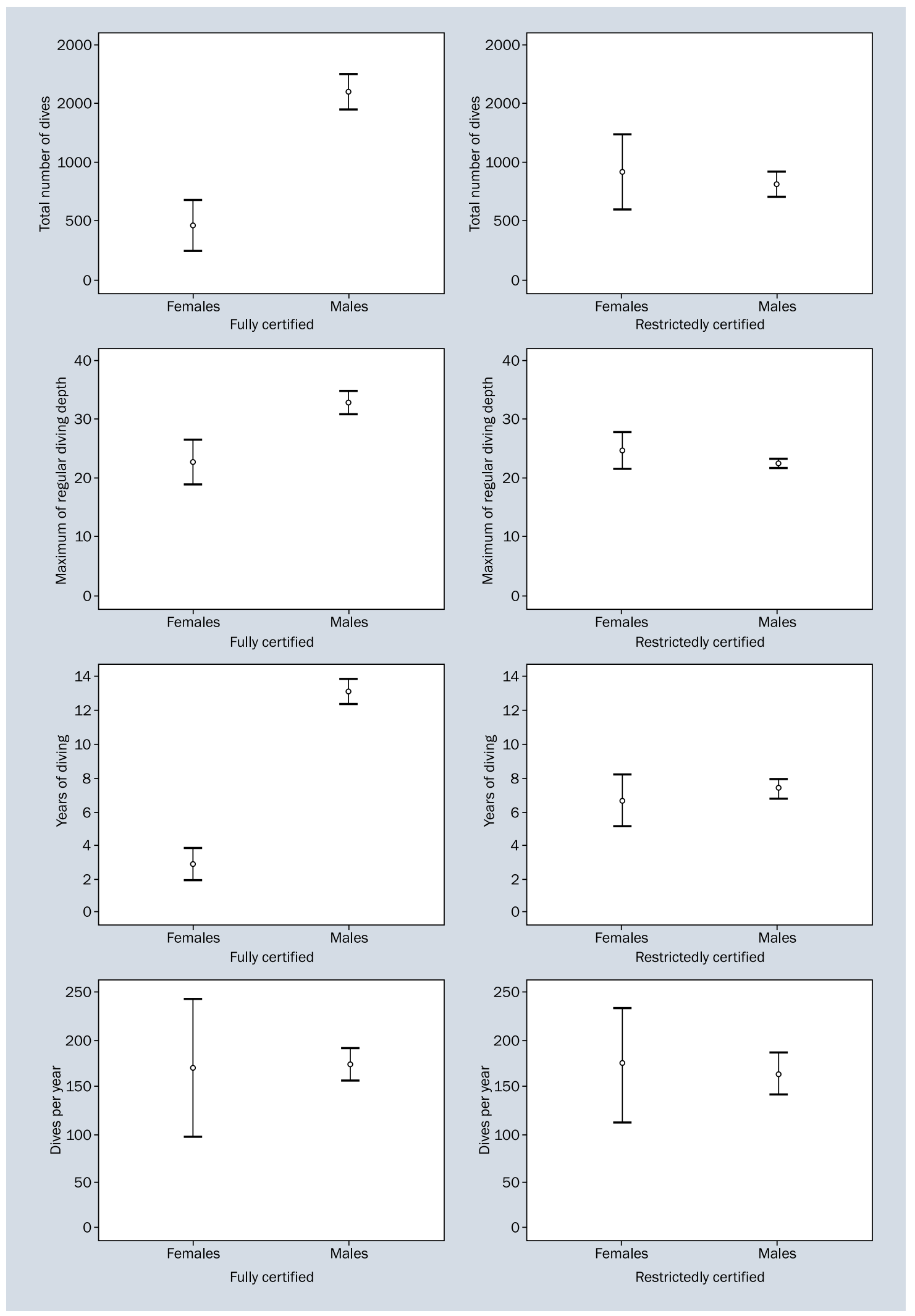

Figure 2. Diving exposure, events during diving, areas and jobs of professional diving; among fully and restricted certified male and female divers. Data from the 'Norwegian diver 2011' project 
Table 4. Unconsciousness during diving, decompression sickness, effect of diving on present health, life threatening or psychologically challenging events during diving; among fully and restricted certified male and female divers. Data from the 'Norwegian diver 2011' project

\begin{tabular}{|c|c|c|c|c|c|c|c|c|}
\hline & \multicolumn{4}{|c|}{ Fully certified } & \multicolumn{4}{|c|}{ Restrictedly certified } \\
\hline & \multicolumn{2}{|c|}{ Female } & \multicolumn{2}{|c|}{ Male } & \multicolumn{2}{|c|}{ Female } & \multicolumn{2}{|c|}{ Male } \\
\hline & $\mathbf{N}$ & $\%$ & $\mathbf{N}$ & $\%$ & $\mathbf{N}$ & $\%$ & $\mathbf{N}$ & $\%$ \\
\hline Experienced a life threatening event & 16 & 66.7 & 714 & 85.6 & 23 & 57.5 & 329 & 66.7 \\
\hline $\begin{array}{l}\text { Experienced a psychologically } \\
\text { challenging event }\end{array}$ & 14 & 58.3 & 657 & 78.8 & 19 & 47.5 & 341 & 69.2 \\
\hline Unconsciousness during diving & 2 & 8.3 & 80 & 9.6 & 2 & 5.0 & 11 & 2.2 \\
\hline Decompression sickness & 4 & 16.7 & 224 & 26.9 & 6 & 15.0 & 48 & 9.7 \\
\hline \multicolumn{9}{|l|}{ Effect of diving on the present health? } \\
\hline Positive & 11 & 45.8 & 210 & 25.2 & 14 & 35.0 & 179 & 36.3 \\
\hline Negative & 4 & 16.7 & 254 & 30.5 & 4 & 10.0 & 52 & 10.5 \\
\hline None & 9 & 37.5 & 352 & 42.2 & 21 & 52.5 & 254 & 51.5 \\
\hline Missing & 0 & 0 & 18 & 2.2 & 1 & 2.5 & 8 & 1.6 \\
\hline
\end{tabular}
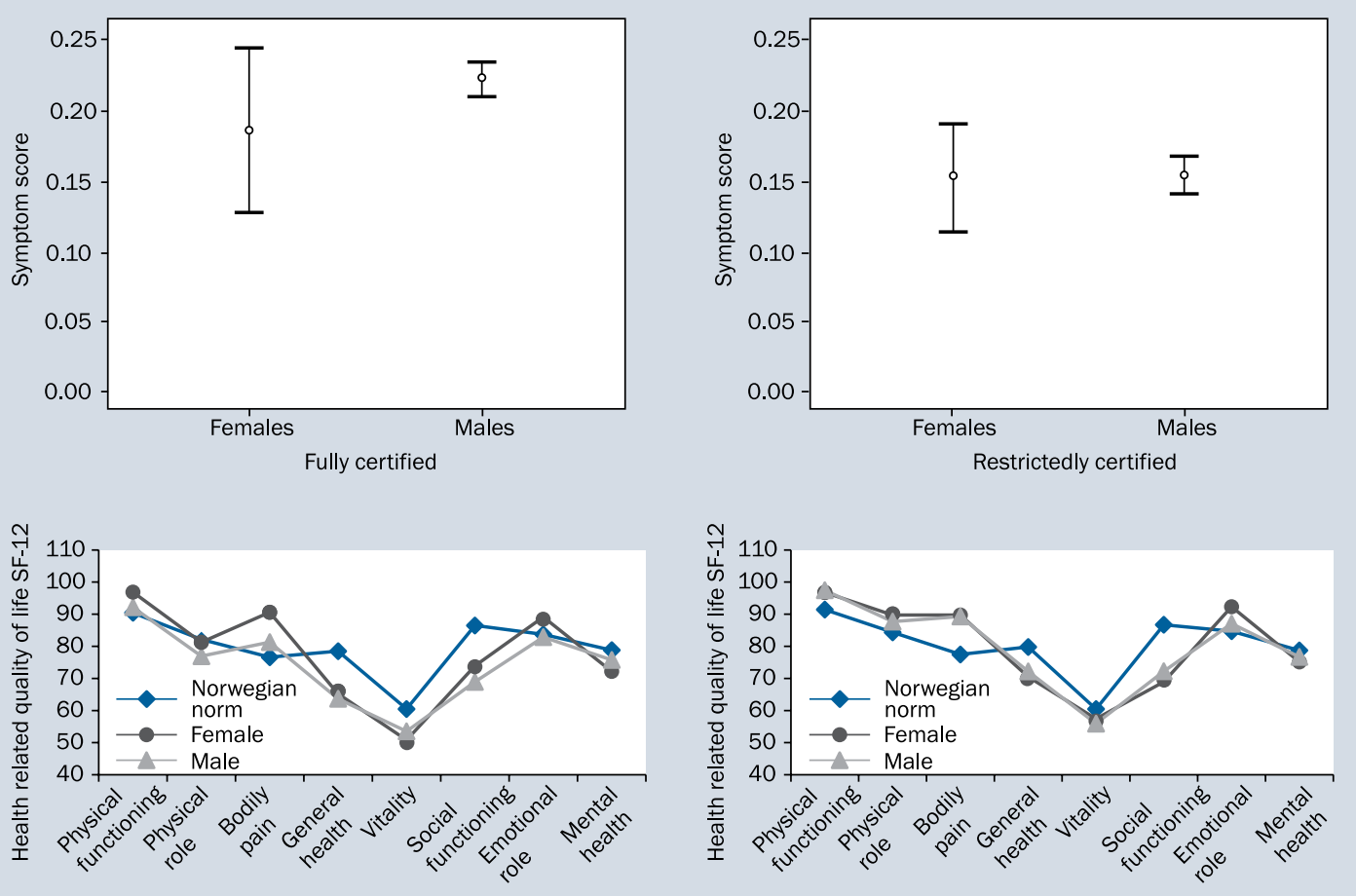

Figure 3. Symptom score, health related quality of life, health effects of diving in male and female divers; among fully and restricted certified male and female divers. Data from the 'Norwegian diver 2011' project

exposure than their male counterparts. Even when fully certified, few female divers were employed in the quay/ /construction sector and more often worked as a teacher/ /instructor or in other, unspecified work. Female divers reported less health problems and a better quality of life than their male colleagues.
Contrary to the widely-held notion that women report more health problems than men $[9,10]$, the female divers in our study reported less such problems than the males. There might be several explanations to this. In our recent paper on health effects in male divers working in different areas of professional diving we found health effects to be 
significantly related to type of work [7]. All aspects of diving exposure seem to be lower among fully certified female divers: years of diving, number of dives, depth, and work strain. This in turn accounts for a lower risk of experiencing unconsciousness, decompression sickness, life threatening events and psychologically challenging events. In line with this, more female divers reported that diving had no negative and even a positive impact on their present health, and the number of symptoms reported was lower than for male divers. Still, a fairly high percentage of former fully certified female professional divers reported having left the diving industry due to health problems.

In Norway at the time of our study, it was mandatory for all professional divers to be registered in the Diver Registry. Inviting all divers from this registry should reduce selection bias. However, the response rate of $49 \%$ and $48 \%$ among female and male divers respectively might still have induced a selection bias.

Generalisation might be a weakness in this study. There were relatively few female divers meeting our inclusion criteria, and when subgrouping these participants into various categories, sample sizes became very small. The small number of female divers made multiparametric analyses impossible causing a weakness in this study. In addition, national differences in regulations regarding sick leave for pregnant women and the duration of maternity leave might render our results less applicable in other countries than Norway.

The questionnaire contains questions from internationally acknowledged instruments as well as question constructed specifically for the "Norwegian diver 2011". Questions were constructed based on knowledge from the diving medical literature at large as well as our previous experience from clinical work and epidemiological research, which almost exclusively looks at male professional divers.

In the present study we set out to find out more about the understudied group of female professional divers. With hindsight, parts of the questionnaire were ill suited for female divers, lacking adequate categories for areas of professional diving and the type of tasks often performed. Hence, for these questions the "other" option was overrepresented in female divers. The "other" option may have concealed a possible different pattern of diving by women. We also lacked pregnancy and family situation as an alternative under "why did you end your professional career?" possibly adding to the "health problem" and "other" alternatives.

\section{CONCLUSIONS}

The female fully certified professional divers in our study had a very short diving career, reported fewer and shallower dives, and chose less physically demanding jobs. They had a higher level of education, reported less health problems and a better quality of life than their male colleagues. The health effects seem to be related to the type of work rather than to gender.

The present study attempted to find out more about the female professional diver. It is still the case that female professional divers are understudied and future research should tailor questionnaires more specifically to women.

\section{ACKNOWLEDGEMENTS}

We would like to thank The Norwegian Labour Inspection Authority who allowed us to use the Diver Registry for research purpose and the staff at the Diving School, Bergen University College for practical assistance, Berit Johannessen previously at the Department of Occupational Medicine, for all of her support in the comprehensive task to acquire the correct national identification numbers of the divers.

We also thank the Norwegian Labour Inspection Authority and the Norwegian Centre of Diving Medicine who funded the questionnaire study the "Norwegian diver 2011".

We also thank MD Suzanne Louise Stannard for help with the English language.

\section{REFERENCES}

1. Mohri M, Torii R, Nagaya K, et al. Diving patterns of ama divers of Hegura Island, Japan. Undersea Hyperb Med. 1995; 22(2): 137-143, indexed in Pubmed: 7633275.

2. Fife CE, St Leger Dowse M. Women and Pressure: Diving and Altitude, Best Publishing Company, Flaggstaff. ISBN: 978-1-930536-54-8. 2010.

3. Irgens $\AA$, Troland $\mathrm{K}$, Thorsen $\mathrm{E}$, et al. Mortality among professional divers in Norway. Occup Med (Lond). 2013; 63(8): 537-543, doi:10.1093/occmed/kqt112, indexed in Pubmed: 24192141.

4. Irgens $\AA$, Grønning M. Cancer risk among professional inshore divers in Norway. Int Marit Health. 2013; 64(4): 202-206, indexed in Pubmed:24408141.

5. Irgens $\AA$, Grønning M, Irgens LM. Pregnancy outcome in partners of male professional divers in Norway. Occup Med (Lond). 2016 [Epub ahead of print], doi: 10.1093/occmed/kqw087, indexed in Pubmed: 27412429.

6. Irgens $\AA$, Troland K, Djurhuus R, et al. Diving exposure and health effects in divers working in different areas of professional diving. Int Marit Health. 2016; 67(4): 235-242, doi: 10.5603/ IMH.2016.0042, indexed in Pubmed: 28009387.

7. Dykkerstudien 2011 [Norwegian diver 2011]. Bergen. Available from: . http://www.helse-bergen.no/no/OmOss/Avdelinger/hyperbar-dykkemedisin/Documents/Dykkerstudien2011.pdf (June 2016, date last accessed).

8. IBM Corp. Released 2011. IBM SPSS Statistics for Windows, Version 22.0. Armonk, NY. : IBM.

9. Kvinners og menns helse - flere likheter enn ulikheter? [Women and men's health - more similarities than inequalities]. Statistics Norway. Available from: . https://www.ssb.no/helse/artikler-og-publikasjoner/kvinners-og-menns-helse-flere-likheter-enn-ulikheter: (Dec 2016, date last accessed).

10. Barsky AJ, Peekna HM, Borus JF. Somatic symptom reporting in women and men. J Gen Intern Med. 2001; 16(4): 266-275, indexed in Pubmed:11318929. 